\title{
Meteorology meets engineering: an interdisciplinary STEM module for middle and early secondary school students
}

\author{
Bradford S Barrett ${ }^{*}$, Angela L Moran ${ }^{2}$ and John E Woods ${ }^{1}$
}

\begin{abstract}
Background: Given the continued need to educate the public on both the meteorological and engineering hazards posed by the severe winds of a tornado, an interdisciplinary science, technology, engineering, and mathematics (STEM) module designed by the faculty from the Oceanography and Mechanical Engineering Departments at the United States Naval Academy (USNA) was developed to engage students ages 12 to 16 in the fields of meteorology and engineering. Interdisciplinary educational modules such as this one are becoming increasingly common components of academic outreach programs, but to our knowledge, this is one of the first to combine the fields of meteorology and engineering. While many studies have examined changes in student engagement and interest in the STEM fields as a result of participating in interdisciplinary activities such as this one, relatively fewer have focused on quantifying changes in student content knowledge. The primary purposes of this paper are to (1) describe our interdisciplinary STEM module in detail and (2) report immediate changes in students' knowledge on basic meteorological and engineering content as a result of their participation in the module.
\end{abstract}

Results: Results from a quick, easy-to-administer assessment instrument given to students immediately before and after their participation in the 1-h module indicated that they learned basic content in both meteorology and engineering. Mean improvement of scores on the assessment questions was $40.2 \%$, a change that was statistically significant at the 95\% confidence level. Other studies that focus on quantifying student learning may wish to lengthen the time between student participation in the module and the administration of the post-module assessment.

Conclusions: Our interdisciplinary module integrated material from meteorology and engineering and was successful at promoting student learning. We recommend that other institutions consider developing similar interdisciplinary STEM activities, and we particularly encourage the development of activities that relate to current events. Finally, we recommend assessing content learning as another way to measure the success of interdisciplinary STEM activities.

Keywords: Interdisciplinary STEM module; Content learning; Module assessment

\section{Background}

Education and outreach campaigns are valuable ways to increase public knowledge and understanding on the hazards posed by severe storm and tornado events (Simmons and Sutter 2011). Outreach to school-age children has been found to be particularly effective (Erickson et al. 2010; National Center for Disaster Preparedness NCDP 2013) in increasing public awareness of severe weather hazards. However, interdisciplinary outreach that focuses

\footnotetext{
* Correspondence: bbarrett@usna.edu

${ }^{1}$ Oceanography Department, United States Naval Academy, Annapolis, MD, USA

Full list of author information is available at the end of the article
}

on improving public knowledge of not only the hazards from tornadoes and high wind but also the need for improved structural design is still critically needed (Prevatt et al. 2012). As one example, it is commonly but incorrectly assumed by the public that tornado casualties cluster with the highest frequency in 'tornado alley', including areas of Texas, Oklahoma, and Kansas, because of the relatively higher frequency of late-spring tornado events there (Erickson et al. 2010). In reality, the region with the highest rate of casualties is the US south, an area that includes eastern Arkansas, western Tennessee, northern Mississippi, and northern Alabama (Ashley 2007), and this is partially a result of both poor engineering design and 
overall population unawareness (Simmons and Sutter 2005; Hall and Ashley 2008; Ashley et al. 2008). Thus, there remains a need for outreach programs that span both meteorology and engineering to close the gap in public awareness on the hazards posed by severe weather. This need motivated the development of an interdisciplinary science, technology, engineering, and mathematics (STEM) module by the faculty from the Departments of Oceanography and Mechanical Engineering at the United States Naval Academy (USNA) for its 2012 summer STEM camp. The short-term goal of the module was to present important content in both meteorology and engineering, two fields not often combined in STEM outreach activities, to increase students' knowledge on basic tornado mechanics and structural engineering principles. The intent of the module was to present basic concepts on both fields and then reinforce student learning via the excitement surrounding the testing of student-built structures in a wind tunnel. The long-term goals of the module were to improve societal awareness of severe weather hazards (e.g., Nutter et al. 2010) and increase participation in STEM fields. This present study assessed the ability of the STEM module to achieve the short-term goal on basic content learning.

Numerous university-level STEM programs have developed educational outreach activities similar to the one described in this paper. Often, the goal of these activities is to increase pre-college students' awareness of, and excitement and participation in, the STEM fields (Jeffers et al. 2004; Stokes et al. 2007). Outreach programs have also been developed specifically for meteorology (e.g., Roebber et al. 2010; Pandya et al. 2011), including those based on research showing the positive impact on students' education by their early involvement in STEM activities and research (e.g., Russell et al. 2007). These outreach programs often provide information about STEM career options and attempt to recruit students to pursue STEM degree programs (Kesidou and Koppal 2004; Swift and Watkins 2004; Thompson and Consi 2007). However, many of these programs have focused on a single discipline, leaving the best practices for interdisciplinary STEM education relatively underdeveloped (Labov et al. 2009). This need to develop and study interdisciplinary STEM activities was reflected in the US Department of Education's 2010 report (Atkinson and Mayo 2010) calling for the National Science Foundation (NSF) and the National Institutes of Health (NIH) to support the development of interdisciplinary STEM activities. As these interdisciplinary outreach programs are created, it is necessary to assess their ability to increase students' knowledge on important science and engineering content (e.g., Nadelson and Callahan 2011) and not just assess their ability to improve student interest in pursuing STEM careers. There is already a strong evidence that disciplinary activities for middle and high school students in the STEM disciplines are especially effective in increasing participants skill levels and awareness on science and engineering concepts and experiment methods (Demetry and Nicoletti 1997; Anderson and Gilbride 2003; Madihally and Maase 2006). However, the effectiveness of STEM activities at increasing students' knowledge on core interdisciplinary content remains relatively understudied. This need, along with the aforementioned needs to continue to educate society on the dangers posed by tornadoes and severe winds and the desire to combine meteorology and engineering in a novel way, motivated both the development and the assessment of the STEM module described in this paper. In the remainder of this paper, we first describe the educational module in greater detail and discuss our methods for its implementation. Because of the novelty of the interdisciplinary module, we give sufficient details so that others would be able to replicate the module if they desired. We then present the results of a targeted assessment instrument that we designed specifically to measure the module's ability to increase student knowledge on basic meteorology and engineering principles. We conclude the paper with a discussion of the results, and we offer suggestions for others interested in assessing content learning in similar interdisciplinary modules.

\section{Methods}

The STEM module, developed as a collaboration between meteorology faculty from the Oceanography Department and engineering faculty from the Mechanical Engineering Department, engaged students in both meteorology and engineering around an exciting topic of current interest: the behavior of structures in the high-wind environment of a tornado. The module's educational objectives were to (1) increase knowledge among middle and high school students about meteorological factors that are associated with tornadoes, especially the climatology and geography of tornado occurrence, (2) increase student understanding of engineering principles behind structure behavior in the kind of high-wind environments common in tornadoes, and (3) engage students in multiple interactive, hands-on activities to reinforce their learning. The assessment goal of the module was to quantify immediate changes in students' knowledge on the core content central to module objectives (1) and (2).

For the STEM camp, the module consisted of a 20- to 25 -min classroom portion followed by a $30-$ to $35-\mathrm{min}$ hands-on activity. Each iteration of the module was attended by between 20 and 25 different students, and this particular module was offered four times each camp week over the 2-week summer period, for a total of eight instances. A total of 160 students participated in the approximately 1 -h module over the entire 2 -week period. To put the module in a broader context, the student participants were part of a week-long residence STEM 
camp in which they arrived on a Monday, resided on campus in the dormitory from Monday through Saturday and participated in 24 different 1-h modules designed and offered by USNA faculty in STEM disciplines. Each day, students participated in four different modules, two in the morning and two in the afternoon. Student participants were aged 12 to 16 , and the module population was 35\% female, 9\% African American, 3\% American Indian or Native Alaskan, 12\% Asian or Pacific American, and 9\% Latino or Hispanic American. Student participants came from all over the United States; however, no other information regarding the prior content knowledge, antecedent interest in STEM fields, or socio-economic background of the student participants was available.

The classroom portion of the module began with the instructor asking students a series of interactive questions regarding the formation and geographic climatology of thunderstorms and tornadoes. Students' hometowns and individual interests, including personal weather experiences, were used to engage and interact with them. Students were asked to consider the possible mechanisms behind the large disparity between thunderstorm occurrence (highest global frequency over tropical land masses) and tornado occurrence (highest global frequency over the US east of the Rocky Mountains). In each module, multiple students were called on to interpret graphics from the National Oceanic and Atmospheric Administration (NOAA) and Ashley (2007), which showed thunderstorm occurrence, tornado occurrence, and tornado casualty occurrence. Discussion of these graphics typically lasted 10-15 minutes. The discussion then turned to the importance of vertical wind shear to the formation of rotating thunderstorms. A deficit of vertical wind shear over tropical areas was seen as the reason why the maximum in global tornado frequency did not align with the maximum in global thunderstorm frequency. The discussion then turned to the mismatch in the highest rate of tornado casualties (in the US mid-south) and the highest rate of tornado frequency (stretching from central Oklahoma northwestward to northeast Colorado). Students were shown a series of photographs of tornado damage, and then they were called on to suggest parts of structures they considered to be weakest. This led to a discussion of engineering load and joint reinforcement and how they relate to the task of mitigating structural damage caused by tornadoes. The engineering portion of the classroom discussion also lasted between 10 and $15 \mathrm{~min}$. At its conclusion, students were given the following instructions and design parameters for the subsequent hands-on activity: in groups of 4 to 5 , they were asked to consider how to build a house out of balsa wood pieces and masking tape that could withstand $150 \mathrm{mph}$ winds. To mimic realworld economical (price) and social (esthetic) constraints, students were told that their supplies would be limited and their structure needed to still look like a house, with walls, a roof, a door, and windows.

In the hands-on portion of the module, students were divided into groups of 4 to 5 , asked to sit at tables set up in the USNA engineering laboratory space, and given 15 to 20 pieces of balsa wood (cut into different rectangular and square shapes 2 to 5 in in size), $1.5 \mathrm{ft}$ of masking tape, and a pre-constructed balsa wood base to serve as the foundation (Figure 1). Before beginning their construction, they were encouraged to be creative in the design of their house. In the building of their house, students were able to see and implement the concept of joint reinforcement, which was introduced to them in the classroom portion. The instructor and undergraduate student aides walked around from table to table, posing questions and encouraging the student teams in their design. For example, groups were also asked to think about how the height of their structure would change its behavior in the wind tunnel. Once a team completed their house, they gathered around the wind tunnel and watched their structure as the wind speed increased. The wind tunnel consisted of a motor and fan, and exhaust output from the fan was narrowed at its exit to accelerate it and direct it toward the student structures anchored on the base track (Figure 2). A manometer calibrated to wind speeds allowed students to estimate the winds their structure was receiving, and flow speeds up to $150 \mathrm{mph}$ were measured at the exit of the fan exhaust. Students were given 10 to $15 \mathrm{~min}$ to

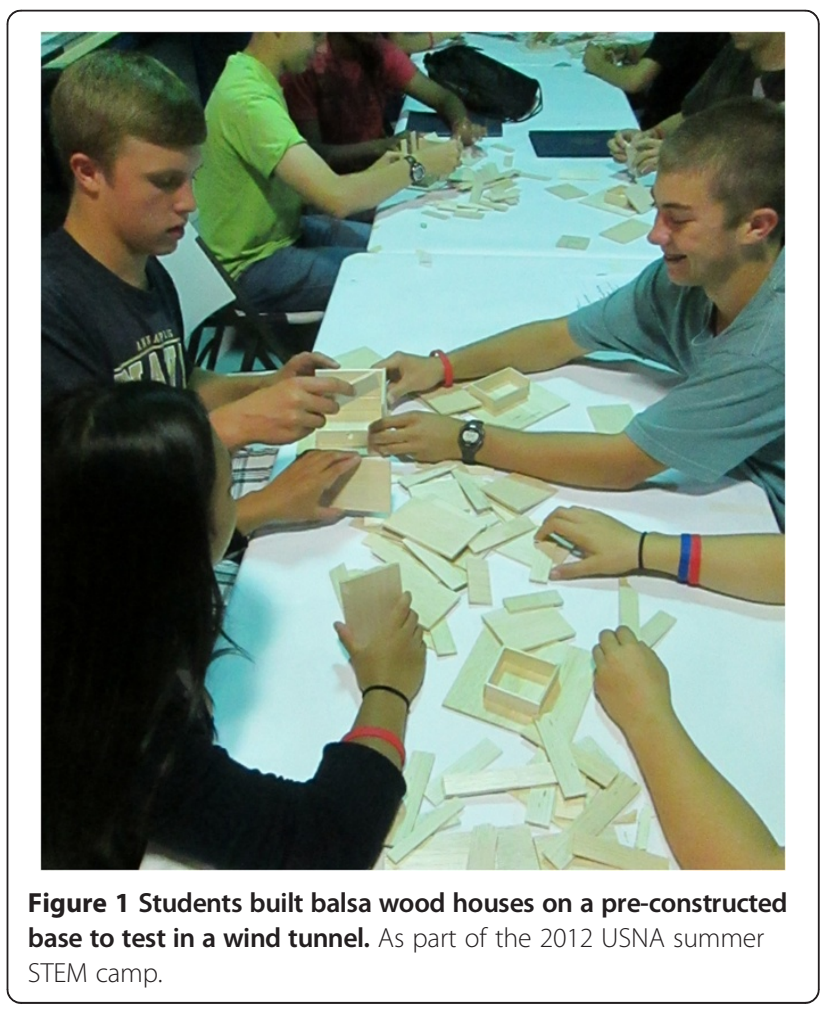


design and build a simple house-like structure out of the allocated balsa wood pieces and tape. Each team then placed their constructed home in the metal base of the wind tunnel (Figure 2), and the motor was turned on. Wind speeds increased approximately $30 \mathrm{mph}$ per $5 \mathrm{~s}$, taking between 25 and $30 \mathrm{~s}$ to reach maximum speed. While the motor was ramping up to full speed, students in that team were asked what part of their house they considered to be the weakest. Typically, students responded that the roof, or the walls, would be the weakest points. The instructor immediately followed up by asking them why those locations might be the weakest in their structures, and students typically responded that those would be the weakest because they have the most connections, because they would bear the greatest load from the wind, or because they are joints that have more points of failure. For safety, students were required to stand behind the wind tunnel outlet and wear safety goggles during the operation of the wind tunnel. If the structure survived the motor ramp up to full speed, it was required to stay intact for an additional 5 to $10 \mathrm{~s}$ before the fan was turned off. During the 2012 module iterations, approximately 50\% of the structures survived their time in the wind tunnel and $50 \%$ did not, and some of the structures exhibited exciting 'catastrophic' failures, whereby they nearly survived but then rapidly exploded in the strong wind environment. Those types of failures proved to be very popular with the students and resulted in many side conversations about why the structures nearly survived but then ultimately failed. If time remained in the module, students were allowed to modify and re-test their house, either adding reinforcements to their structure if it failed in the tunnel or removing reinforcements if their structure survived the wind tunnel. For the additional rounds of testing, students were no longer limited by supplies. They sometimes ended up wrapping their structures in tape and then placing it in the wind tunnel, an experiment in which they found that tape was a surprisingly strong adhesive. The entire module, including the classroom and hands-on portions, lasted 50 to $55 \mathrm{~min}$.

\section{Assessment: instrument design and implementation}

To quantitatively assess student content learning in meteorology and engineering, students took a four-question quiz upon entering the classroom portion and then retook the quiz upon departing the classroom portion. In each instance, students were given $5 \mathrm{~min}$ to complete the four questions. All student quizzes were conducted anonymously and voluntarily, although those who did complete the quizzes were asked to write their first names on their papers so that before and after questions could be matched to the same person. During the 2 -week period, 146 out of 160 question responses were received. The paper assessment quizzes were destroyed after the questions were graded, with only non-identifying information such as scores on the assessments retained for research purposes. The two tornado-related questions were open-ended, and the two engineering-related questions were multiple choice. Scores on the multiple choice questions were determined objectively (only the correct answer was awarded three points), and to reduce some of the subjectivity in the scoring of the open-ended questions, they were scored by two separate instructors, with the responses given a score of $0,1,2$, or 3 , with 3 being the highest. Scores from the two instructors were then averaged. Partial credit on the open-ended questions was awarded for answers that partially captured the basics of tornado formation and climatology. This style of short assessment that takes a minimal amount of time away from the instructional module itself is similar to the 'daily quiz' of Kwan (2010). Although it is one of the shorter assessment instruments available, it has been found to be a way to immediately assess student learning (Kwan 2010). Because the assessment is administered immediately after an activity, it is not intended to quantify long-term retention. Furthermore, the open-ended meteorology assessment

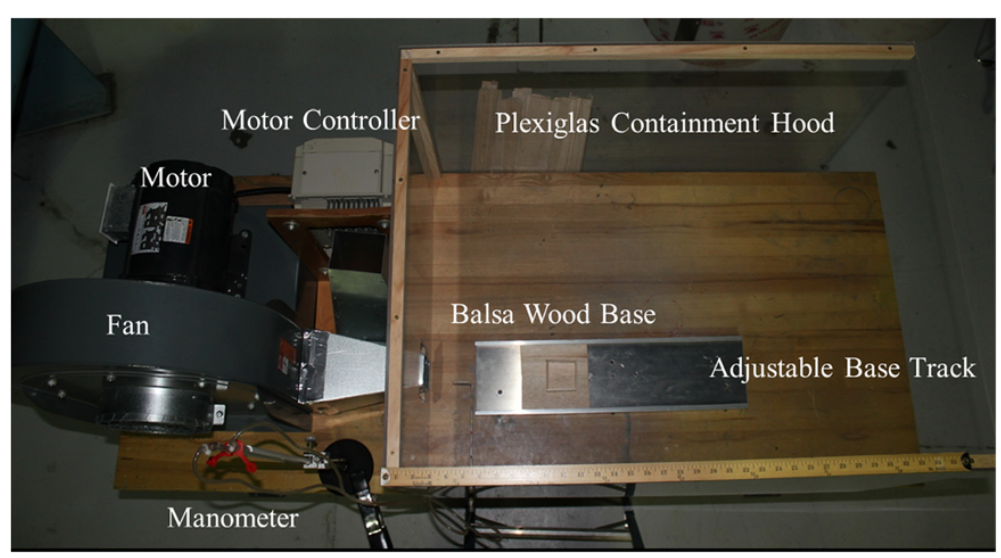

Figure 2 Overhead view of the wind tunnel. 
questions were similar to those of Barrett and Woods (2012), who designed a short assessment instrument with open-ended questions and used that instrument to assess student learning in a meteorology STEM activity. The engineering assessment questions were designed specifically to address the issues of structural integrity in a high-wind environment that were tested in the hands-on portion of the module. The quantitative assessment questions were created to fit into the 'recall' and 'understanding' levels of Bloom's taxonomy of higher-order thinking (Krathwohl 2002; Bloom et al. 1956). The hands-on portion of the module allowed students to use this knowledge in a new situation, and thus, it was designed to fit into the 'application' level of Bloom's taxonomy. The questions given to students, as well as the assessment results, are presented in Table 1.

\section{Results}

Results of the learning assessment showed that immediate student knowledge of basic content in both meteorology and engineering topic areas increased as a result of their participation in the 1-h module (Table 1). The first two questions dealt with meteorology and geography, asking students which parts of the world experienced the most thunderstorms and tornadoes. At the start of the module, students scored an average of $36.3 \%$ and $41.8 \%$, respectively, out of a maximum score of $100 \%$. After participating in the module, mean scores improved to $84.2 \%$ and $80.1 \%$, respectively. These differences between the means of each question were statistically significant at the $95 \%$ confidence level using the Student's $t$ test with a sample size $n$ of 146. The final two questions tested student knowledge of engineering and structural design. Here also, student scores at the start of the module were moderate to low, averaging $68.5 \%$ and $30.8 \%$, respectively. Similar to the results of the meteorology questions, after participating in

Table 1 Learning assessment results from a sample of $n=146$

\begin{tabular}{lcc}
\hline Question & $\begin{array}{c}\text { Pre-STEM } \\
\text { score }\end{array}$ & $\begin{array}{c}\text { Post-STEM } \\
\text { score }\end{array}$ \\
\hline $\begin{array}{l}\text { What regions of the world typically have the } \\
\text { most thunderstorms? }\end{array}$ & $36.3 \%$ & $84.2 \%$ \\
What regions of the world typically have the & $41.8 \%$ & $80.1 \%$ \\
most tornadoes? & & \\
What part of a house do you consider to be & $68.5 \%$ & \\
the most structurally vulnerable during the & & \\
high winds of a tornado? a. Walls, b. Roof, c. & & \\
Bathroom, d. Doors, e. Basement & & \\
What is something that can be done to a & $30.8 \%$ \\
house's structure to make it better resistant to & & \\
tornado damage? a. Open windows as a & & \\
tornado approaches, b. Tie walls and joints to \\
reduce load, c. Decrease roof slope to allow \\
winds to pass over at higher speeds, d. Install \\
garage door, e. Remove ties between house \\
and its foundation
\end{tabular}

Maximum score for each question was $100 \%$. the module, student scores increased to $83.6 \%$ and $90.4 \%$, respectively. Here again, the differences in means was statistically significant at the $95 \%$ confidence level. When using a paired test, whereby individual students' improvements were tracked, mean scores improved across all four questions by $40.2 \%$. Again, this result was statistically significant at the $95 \%$ confidence level. The results of these four questions show that students clearly learned details of the geography and climatology of thunderstorm and tornado occurrence, an outcome that directly supports the first objective of the module. Furthermore, students also significantly increased their understanding of structural engineering, particularly with respect to the need to reinforce joints by tying them together to reduce load, an outcome in direct support of the second objective of the module. Together, the statistically significant improvement in scores on all four of the questions in the learning assessment instrument shows that this interdisciplinary STEM module was successful at increasing students' content knowledge in both meteorology and engineering.

Although the assessment results were statistically significant, it is important to recognize their limitations. First, in the interest of maximizing student time actually participating in the module, the assessment instrument consisted of only four questions. This brevity precluded more substantial inquiry into content learning, particularly inquiry into any changes in higher-order knowledge (such as the 'applying' or 'analyzing' categories of Bloom's taxonomy). Second, the assessment was administered immediately after the classroom portion of the module. Thus, while it revealed significant changes in student knowledge about meteorology and engineering, it only quantified short-term learning, not long-term retention. However, since students only participated in the module for approximately $1 \mathrm{~h}$, these results aligned with expectations of changes in student knowledge at the 'recall' and 'understanding' levels.

\section{Conclusions}

An interdisciplinary STEM module, given eight times to 160 participants aged 12 to 16 during a 2-week period during the June 2012 USNA summer STEM camp, was designed to increase student awareness of the basic meteorological and climatological factors associated with tornadoes and to increase their understanding of the basic engineering principles that govern structure behavior in high-wind environments. The module consisted of a 20 - to 25 -min classroom portion followed by a $30-$ to 35 -min laboratory exercise. The classroom portion was interactive and personalized to students' hometowns and individual experiences, and it focused on the climatology and meteorology of tornado formation and engineering principles behind tornado damage. The hands-on portion was also interactive and allowed 
students to creatively design a structure that they considered would survive wind speeds up to $150 \mathrm{mph}$.

Assessment outcomes indicated that students learned content in both subjects, with mean improvement of paired samples on the before-and-after questionnaire of $40.2 \%$. This result is important because many studies that evaluated the success of STEM modules focused on the impact on students' interest in STEM and the STEM fields, not necessarily on their learning of STEM content. Here, we documented content learning as a result of participation in an interdisciplinary STEM activity, a result that is important because it shows the value of interdisciplinary STEM activities. Because the most exciting result for the students seemed to be was when a structure failed in the high-wind environment of the wind tunnel, particularly so after withstanding the winds for several seconds, future iterations of this module could take advantage of this enthusiasm by including higher-order thinking questions related to the hands-on activity in the wind tunnel. One such way to do this could be to ask students to predict, before testing their structure in the tunnel, (1) whether, and why, they thought their structure would fail (perhaps by giving a percentage chance of survival from $0 \%$ to $100 \%$ ), and then (2) using concepts from the classroom portion of the module, predict what part of their structure they thought would fail first. Once they completed these hypotheses, student groups would be able to test them immediately in the wind tunnel. In the 2012 iterations of the module, students were sometimes asked these questions, although future iterations could be more formal with this kind of assessment, as student responses would be another indication of whether they learned the key content of the module. Also, when student groups whose structures were destroyed in the wind tunnel are given a chance to rebuild and try again, they could be asked to discuss the reasons for each change to their structure. Students whose homes survived would be given new materials and told to renovate and then test again. Finally, to quantify the impact of the hands-on part of the module on student learning, another post-module assessment quiz could be given after the hands-on portion that included higher-order thinking questions created to assess student learning as a result of the design-build-test phase.

Given the increase in the number of academic institutions offering these types of STEM outreach activities, it is important to assess their effectiveness. Recent studies have found that student participation in these activities impacts them in a variety of ways, including influencing their choice of undergraduate major, their impression of the STEM disciplines, and their desire to pursue a STEM career. However, relatively few studies exist that measure the effectiveness of these types of STEM activities in terms of student learning of core STEM content. Thus, institutions that offer these types of STEM outreach programs may wish to consider including content-focused assessment instruments, similar to the one used in this study, in addition to their other assessment instruments. This study has shown that content assessment can be a quick, easyto-administer measure of basic student content learning that offers another way to assess effectiveness of a STEM activity. We suggest that such assessment instruments include questions specifically tailored for the content of that particular STEM activity. We also suggest that the postassessment instrument could be administered later than it was in our study, as knowledge recall is often at its highest immediately after the information is presented. Finally, we suggest that institutions consider creating and implementing interdisciplinary outreach activities similar to the one described here, as a potentially new way to engage students around core disciplinary content.

\section{Consent}

Parents (or legal guardians) of all students in this case signed a consent statement prior to this study.

\section{Abbreviations}

NCDP: National Center for Disaster Preparedness; NIH: National Institutes of Health; NOAA: National Oceanic and Atmospheric Administration; NSF: National Science Foundation; STEM: science, technology, engineering, and mathematics; USNA: United States Naval Academy.

\section{Competing interests}

The authors declare that they have no competing interests.

\section{Authors' contributions}

BB carried out the module and assessment, conceived of the study, and drafted the manuscript. All authors designed and tested the module and read and approved the final manuscript.

\section{Acknowledgements}

The authors thank Sarah Durkin for her helpful suggestions to improve the manuscript. We also thank the three anonymous reviewers and the editor for their efforts and many comments regarding the structure of this paper. The United States Naval Academy STEM programs are partially funded by grants from the Office of Naval Research.

\section{Author details}

'Oceanography Department, United States Naval Academy, Annapolis, MD, USA. ${ }^{2}$ Mechanical Engineering Department, United States Naval Academy, Annapolis, MD, USA.

Received: 25 February 2014 Accepted: 28 July 2014

Published: 1 September 2014

\section{References}

Anderson, LS, \& Gilbride, KA. (2003). Preuniversity outreach: encouraging students to consider engineering careers. Global Journal of Engineering Education, 7(1), 87-93.

Ashley, WS. (2007). Spatial and temporal analysis of tornado fatalities in the United States: 1880-2005. Weather and Forecasting, 22(6), 1214-1228.

Ashley, WS, Krmenec, AJ, \& Schwantes, R. (2008). Vulnerability due to nocturnal tornadoes. Weather and Forecasting, 23(5), 795-807.

Atkinson, RD, \& Mayo, M. (2010). Refueling the U.S. innovation economy: fresh approaches to science, technology, engineering and mathematics (STEM) education. Washington, DC: Information Technology and Innovation Foundation. Available on-line at http://www.itif.org/files/2010-refuelinginnovation-economy.pdf.

Barrett, BS, \& Woods, JE. (2012). Using the amazing atmosphere to foster student learning and interest in meteorology. Bulletin of the American Meteorological Society, 93(3), 315-323. 
Bloom, B, Englehart, M, Furst, E, Hill, W, \& Krathwohl, D. (1956). Taxonomy of educational objectives: the classification of educational goals. Handbook l: cognitive domain. New York, Toronto: Longmans, Green.

Demetry, C, \& Nicoletti, DW. (1997). Camp REACH: an engineering summer camp for middle school girls. In Proceedings of the 1997 Frontiers in Education Annual Conference. New York: Institute of Electrical and Electronics Engineers.

Erickson, SA, Shafer, MA, \& Grizzle, DR. (2010). Lone Grove, Oklahoma February tornado: response, impacts and lessons learned. Fifth Symposium on Policy and Socio-economic Research. Amererican Meteorological Society. J15.2.

Hall, SG, \& Ashley, WS. (2008). Effects of urban sprawl on the vulnerability to a significant tornado impact in Northeastern Illinois. Natural Hazards Review, 9(4), 209-219.

Jeffers, A, Safferman, A, \& Safferman, S. (2004). Understanding K-12 engineering outreach programs. Journal of Professional Issues in Engineering Education and Practice, 130(2), 95-108.

Kesidou, S, \& Koppal, M. (2004). Supporting goals-based learning with STEM outreach. Journal of STEM Education: Innovations and Research, 5(3-4), 4-10.

Krathwohl, DR. (2002). A revision of Bloom's taxonomy: an overview. Theory Into Practice, 41(4), 212-218.

Kwan, F. (2010). Formative assessment: the one-minute paper vs the daily quiz. Journal of Instructional Pedagogies, 5, 1-8.

Labov, JB, Singer, SR, George, MD, Schweingruber, HA, \& Hilton, ML. (2009). Effective practices in undergraduate STEM education part 1: examining the evidence. CBE Life Sciences Education, 8(3), 157-161.

Madihally, S, \& Maase, E. (2006). Introducing biomedical and biochemical engineering for k-12 students. In Proceedings of the American Society for Engineering Education Annual Conference \& Exhibition. Chicago: American Society for Engineering Education.

Nadelson, LS, \& Callahan, J. (2011). A comparison of two engineering outreach programs for adolescents. Journal of STEM Education: Innovations and Research, 12(1), 43-54.

National Center for Disaster Preparedness (NCDP). (2013). At the crossroads of recovery: Joplin, Missouri six months after the May 21, 2011 tornado. New York: Columbia University Press.

Nutter, PA, Gaarder, D, Gunderson, J, \& Drennen, C. (2010). Educating citizens about severe weather awareness following the 22 May 2008 northern Colorado tornado. In 19th Symposium on Education: American Meteorological Society. J14.2.

Pandya, R, Smith, D, Ackerman, SA, Brahma, PP, Charlevoix, DJ, Foster, SQ, Gaertner, VK, Lee, TF, Hayes, MJ, Mostek, A, Murillo, ST, Murphy, KA, Olsen, L, Stanitski, DM, \& Whittaker, T. (2011). A summary of the 18th AMS Symposium on Education. Bulletin of the American Meteorological Society, 92(1), 61-64.

Prevatt, DO, van de Lindt, JW, Back, EW, Graettinger, AJ, Pei, S, Coulbourne, W, Gupta, R, James, D, \& Agdas, D. (2012). Making the case for improved structural design: tornado outbreaks of 2011. Journal of Leadership Management in Engineering, 12(4), 254-270.

Roebber, RJ, Westendorf, M, \& Meadows, GR. (2010). Innovative weather: a new strategy for student, university, and community relationships. Bulletin of the American Meteorological Society, 91(7), 877-888.

Russell, SH, Hancock, MP, \& McCullough, J. (2007). The pipeline: benefits of undergraduate research experiences. Science, 316(5824), 548-549.

Simmons, KM, \& Sutter, D. (2005). WSR-88D radar, tornado warnings, and tornado casualties. Weather and Forecasting, 20(3), 301-310.

Simmons, KM, \& Sutter, D. (2011). Economic and Societal Impacts of Tornadoes (p. 282): American Meteorological Society.

Stokes, PJ, Baker, GS, Briner, JP, \& Dorsey, DJ. (2007). A multifaceted outreach model for enhancing diversity in the geosciences in Buffalo, NY. Journal of Geoscience Education, 55(6), 581-588.

Swift, TM, \& Watkins, SE. (2004). An engineering primer for outreach to K-4 education. Journal of STEM Education: Innovations and Research, 5(3), 67-76.

Thompson, MK, \& Consi, TR. (2007). Engineering outreach through college preorientation programs: MIT discover engineering. Journal of STEM Education: Innovations and Research, 8(3), 75-82.

doi:10.1186/2196-7822-1-6

Cite this article as: Barrett et al:: Meteorology meets engineering: an interdisciplinary STEM module for middle and early secondary school students. International Journal of STEM Education 2014 1:6. 